\title{
Inspirational Women in Surgery: Professor Vijayalakshmi Deshmane, MS (Surgical Oncologist, India)
}

\author{
Mallika Tewari $^{1} \cdot$ Savio George Barreto $^{2,3}$ (1)
}

Accepted: 17 February 2022/Published online: 5 March 2022

(C) The Author(s) under exclusive licence to Société Internationale de Chirurgie 2022

Professor Vijayalakshmi Deshmane (Fig. 1a) was born in a slum (an area of a city where living conditions are poor and where the houses are in bad condition) in Gulbarga (now Kalburgi) in the South of India. She was the eldest child (of eight) of late. Baburao Deshmane a textile mill worker (who was also involved in the Indian freedom struggle), and late. Ratnamma, who was a vegetable seller (Fig. 1b). As a child, Professor Deshmane vividly remembers her brother and herself helping their mother sell vegetables. In her opinion, Professor Deshmane regards her father as a visionary who spared no effort to encourage all his children to aspire to intellectual excellence, including persuading her to become a surgeon-which would have been considered preposterous at the time-not only because she was a woman, but a woman from the underprivileged, backward classes (Fig. 1).

Professor Deshmane graduated in Medicine (MBBS) from the Hubli Medical College. Her mother's sacrifice to sell her 'Mangalsutra' (the auspicious thread worn by the bride as a sign of being married in the Hindu tradition) to pay for Professor Deshmane's admission fees to the MBBS course is something she will not forget. She went on to complete general surgical training (Master of Surgery) from the Government Medical College, Bellary, Karnataka. Professor Deshmane trained in surgical oncology at two of

Mallika Tewari

drmtewari@gmail.com

1 Department of Surgical Oncology, Banaras Hindu University, Varanasi, Uttar Pradesh, India

2 College of Medicine and Public Health, Flinders University, Adelaide, South Australia, Australia

3 Division of Surgery and Perioperative Medicine, Flinders Medical Centre, Bedford Park, Adelaide, South Australia, Australia
India's premier cancer centres, namely, the Tata Memorial Centre, Mumbai and Kidwai Memorial Institute of Oncology, Bengaluru, Karnataka. Professor Deshmane found supportive mentors in Dr. G. Gowda, Dr. Bhargava, Dr. Desai, Dr. Rao, Prof. P. Gowda, Prof. M. Krishnan, Prof. S. Shetty, Prof. M. Budihal, Prof. C. Raghu, Dr. R. Deshpande, and Dr. R. Deo throughout her medical and surgical training.

Over 3 decades of service as a Breast cancer surgical expert at the Kidwai Memorial Institute of Oncology, where she ultimately assumed the position of Head of Department and Director-in-Charge, Professor Deshmane always aimed to inculcate a culture that promoted the practice of evidence-based medicine. She initiated a number of early evidence-based practices that eventually became standard of care within the Department including the performance of outpatient mastectomies, the use of Tamoxifen ${ }^{\circledR}$, instead of the performance of oophorectomy, as well as the use of adjuvant chemotherapy. She led the Phase III trial comparing Arzoxifene ${ }^{\circledR}$ with Tamoxifen ${ }^{\circledR}$ for locally advanced, or metastatic, breast cancer [1]. Professor Deshmane also led a study examining the role of Exemestane ${ }^{\circledR}$ in post-menopausal women with hormonedependent breast cancer. Her desire to educate individuals on the breast cancer went beyond the realm of her surgical trainees. In her capacity as President of the Karnataka Cancer Society, she endeavoured to raise public awareness on breast cancer by organising numerous programs. Her reputation in the field resulted in her appointment as Inspector by the Medical Council of India involved in the processes of recognition of Surgical Oncology training in India for the subspecialist degree, Master of Chirurgie (MCh).

Following retirement from surgical practice in 2015, Professor Deshmane not only continued to involve herself 
Fig. 1 a Professor

Vijayalakshmi Deshmane,

b Professor Deshmane's parents

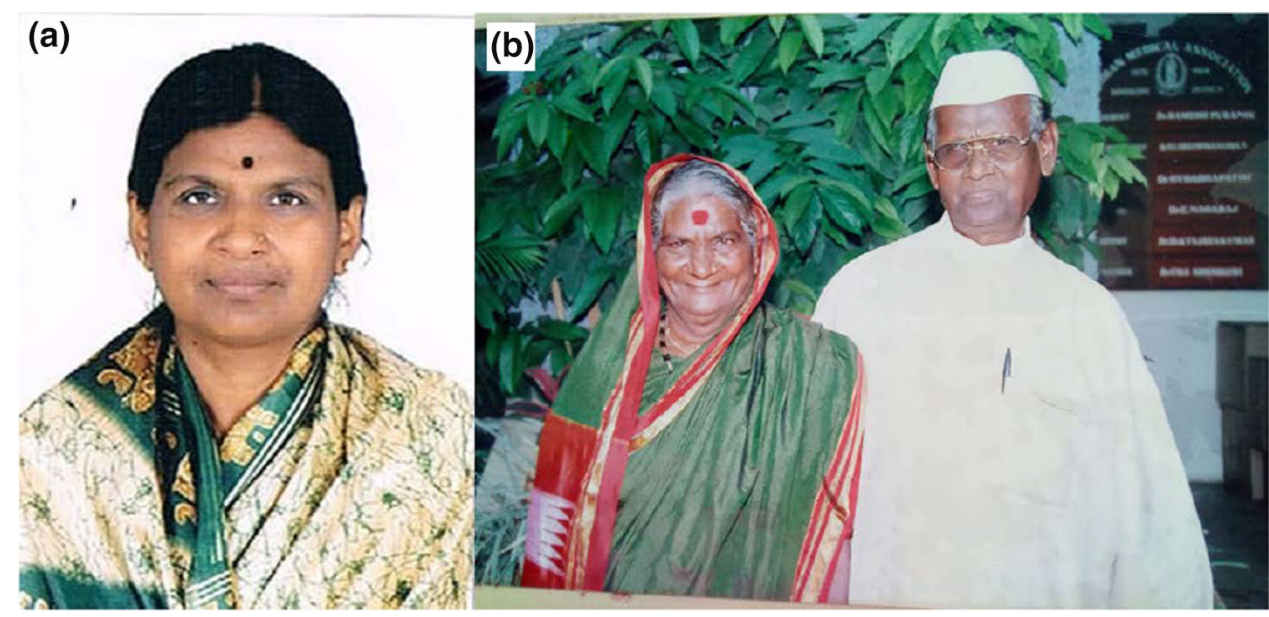

in raising awareness on breast cancer issues amongst the lay public, she also took on the mantle, serving as the President of Abalashrama, in Bengaluru. This shelter for orphaned girls provides these girls with the necessary life skills to help them become self-sufficient. Her selfless service, humility, sincerity and integrity over decades have not gone unnoticed. She is the proud recipient of numerous awards and accolades in the southern Indian state of Karnataka.

Her message to young aspiring surgeons is one of hope and gratitude. She implores young surgeons to respect patients and their families. Surgeons should strive not only to be technically sound, but must develop themselves as holistic clinicians supporting their patient's needs even if surgery is not a treatment option. Surgeons must keep up with the times embracing modern technologies to enhance the delivery of care to their patients.

\section{Funding None.}

\section{Reference}

1. Deshmane V, Krishnamurthy S, Melemed AS et al (2007) Phase III double-blind trial of arzoxifene compared with tamoxifen for locally advanced or metastatic breast cancer. J Clin Oncol 25:4967-4973

Publisher's Note Springer Nature remains neutral with regard to jurisdictional claims in published maps and institutional affiliations. 